\title{
Fourth-Order Four-Point Boundary Value Problem: A Solutions Funnel Approach
}

\author{
Panos K. Palamides ${ }^{1}$ and Alex P. Palamides ${ }^{2}$ \\ ${ }^{1}$ Naval Academy of Greece, 45110 Piraeus, Greece \\ ${ }^{2}$ Technological Educational Institute of Piraeus, Department of Electronic Computer Systems, \\ P.Ralli and Thivon 250, 12240 Athens, Greece \\ Correspondence should be addressed to Panos K. Palamides, ppalam@otenet.gr
}

Received 9 April 2012; Revised 26 May 2012; Accepted 10 June 2012

Academic Editor: Michael Tom

Copyright (C) 2012 P. K. Palamides and A. P. Palamides. This is an open access article distributed under the Creative Commons Attribution License, which permits unrestricted use, distribution, and reproduction in any medium, provided the original work is properly cited.

We investigate the existence of positive or a negative solution of several classes of fourpoint boundary-value problems for fourth-order ordinary differential equations. Although these problems do not always admit a (positive) Green's function, the obtained solution is still of definite sign. Furthermore, we prove the existence of an entire continuum of solutions. Our technique relies on the continuum property (connectedness and compactness) of the solutions funnel (Kneser's Theorem), combined with the corresponding vector field.

\section{Introduction}

In recent years, boundary-value problems for second and higher order differential equations have been extensively studied. They are used to describe a large number of physical, biological, and chemical phenomena. The work of Timoshenko [1] on elasticity, the monograph by Soedel [2], the paper by Palamides [3] on deformation of elastic membrane, and the work of Dulàcska [4] on the effects of soil settlement are rich sources of such applications.

Pietramala [5] presented some results on the existence of multiple positive solutions of a fourth-order differential equation subject to nonlocal and nonlinear boundary conditions that models a particular stationary state of an elastic beam with nonlinear controllers.

In [6], Erbe and Wang by using a Green's function and Krasnoselskii's fixed point theorem in a cone proved the existence of a positive solution of the following boundary value problem: 


$$
\begin{gathered}
x^{\prime \prime}(t)=f(t, x(t)), \quad 0 \leq t \leq 1, \\
a x(0)-b x^{\prime}(0)=0, \quad c x(1)+d x^{\prime}(1)=0,
\end{gathered}
$$

under positivity and sub or superlinearity of the nonlinearity and moreover $\delta=a d+b c+a c>$ 0 .

The literature for previous BVP is voluminous. Suggestively, we refer to [7-11] and the references therein. The monograph of Agarwal et al. [12] contains excellent surveys of known results.

Recently, an increasing interest in studying the existence of solutions and positive solutions to boundary-value problems for higher order differential equations is observed, see for example [13-17]. Especially, Graef and Yang [15] and Hao et al. [18] proved existence results on nonlinear boundary-value problem for fourth-order equations.

Also, Ge and Bai [19] by using a fixed point theorem due to Krasnoselskii and Zabreiko in [20] investigated the fourth-order nonlinear boundary value problem as

$$
\begin{gathered}
u^{(4)}(t)=-f\left(t, u(t), u^{\prime \prime}(t)\right), \quad 0<t<1, \\
u(0)=u(1)=0, \\
a u^{\prime \prime}\left(\xi_{1}\right)-b u^{\prime \prime \prime}\left(\xi_{1}\right)=0, \quad c u^{\prime \prime}\left(\xi_{2}\right)+d u^{\prime \prime \prime}\left(\xi_{2}\right)=0 .
\end{gathered}
$$

Precisely, they proved the next result.

Theorem 1.1. Assume that

$\left(H_{1}\right) a, b, c$, and $d$ are nonnegative constants satisfying $\rho=a d+b c+a c\left(\xi_{2}-\xi_{1}\right) \neq 0, b-a \xi_{1} \geq 0$ and $0 \leq \xi_{1}<\xi_{2} \leq 1$;

$\left(H_{2}\right)$ the nonlinearity can be separated as $f(t, u, v)=p(t) g(u)+q(t) h(v)$, where $g, h: \mathbb{R} \rightarrow \mathbb{R}$ are continuous;

$$
\lim _{u \rightarrow \infty} \frac{g(u)}{u}=\lambda, \quad \lim _{v \rightarrow \infty} \frac{h(v)}{v}=\mu,
$$

and $p, q \in C[0,1]$. Moreover, there exists some $t_{0} \in[0,1]$ such that $p\left(t_{0}\right) g(0)+$ $q\left(t_{0}\right) h(0) \neq 0$, and there exists a continuous nonnegative function $w:[0,1] \rightarrow \mathbb{R}^{+}$such that $|p(s)|+|q(s)| \leq w(s)$ for each $s \in[0,1]$;

$\left(H_{3}\right) \max \{|\lambda|,|\mu|\}<\min \left\{1 / L_{1}, 1 / L_{2}\right\}$, where $L_{i}(i=1,2)$ are constants depending on $p(t)$ and $q(t)$. Then the BVP (1.2) admits at least one nontrivial solution $u \in C^{2}[0,1]$.

Similarly Cui and Zou [21], on the base of a fixed point theorem, studied the BVP

$$
\begin{gathered}
x^{(4)}(t)=p(t) f(x(t)), \quad t \in(0,1), \\
x(0)=x(1)=x^{\prime}(0)=x^{\prime}(1)=0,
\end{gathered}
$$


to the case where $f(x)$ is monotone and either superlinear or sublinear, mainly under the assumption

$$
\int_{0}^{1} p(s) f\left(s 2(1-s)^{2}\right) d s<1
$$

Finally, Infante and Pietramala [22] proved some results on the existence of positive solutions for some cantilever fourth-order differential equation subject to nonlocal and nonlinear boundary conditions.

Restricting our consideration on the linear case, notice as far as the author is awake, that only the conditions in (1.2) have been studied, where the constants $a, b, c$, and $d$ are nonnegative.

In a recent paper, Kelevedjev et al. [23] proved the existence of a positive and/or a negative solution for the boundary value problem (1.2), mainly under superlinearity conditions on the nonlinearity. Moreover, they exhibited existence results to the following differential equation:

$$
u^{(4)}(t)=-f\left(t, u(t), u^{\prime \prime}(t)\right), \quad 0<t<1,
$$

subject to the boundary conditions as

$$
u(0)=u(1)=0, \quad a u^{\prime \prime}\left(\xi_{1}\right)+b u^{\prime \prime \prime}\left(\xi_{1}\right)=0, \quad c u^{\prime \prime}\left(\xi_{2}\right)-d u^{\prime \prime \prime}\left(\xi_{2}\right)=0 .
$$

Moreover, in an interesting paper [24], Anderson and Avery, by applying a generalization of the Leggett-Williams fixed point theorem, proved the existence of at least three positive solutions to the BVP as

$$
\begin{gathered}
x^{(4)}(t)=-f(x(t)), \quad 0 \leq t \leq 1, \\
x(0)=x^{\prime}(q)=x^{\prime \prime}(r)=x^{\prime \prime \prime}(1)=0, \quad 0<q<r<1 .
\end{gathered}
$$

In this paper, we relax the assumptions in [23] and extend the above results to the case where the constants $c$ and $d$ are not necessarily positive and the nonlinearity is asymptotically linear and not necessarily separated, that is we study the BVP

$$
\begin{gathered}
u^{(4)}(t)=f\left(t, u(t), u^{\prime \prime}(t)\right), \quad 0<t<1, \\
u(0)=u(1)=0, \quad a u^{\prime \prime}\left(\xi_{1}\right)+b u^{\prime \prime \prime}\left(\xi_{1}\right)=0, \quad c u^{\prime \prime}\left(\xi_{2}\right)+d u^{\prime \prime \prime}\left(\xi_{2}\right)=0,
\end{gathered}
$$

with $a, b, c$, and $d \geq 0$. Instead of the assumptions $\rho=a d+b c+a c\left(\xi_{2}-\xi_{1}\right) \neq 0$ and /or $b-a \xi_{1} \geq 0$ in [20], we need only the condition

$$
\rho^{*}:=a c\left(\xi_{2}-\xi_{1}\right)+a d-b c>0
$$


Also the constants $\mu$ and $\mu^{*}$ (see the assumptions $\left(B_{1}\right)-\left(B_{3}^{*}\right)$ below) satisfy different (see (2.7)) inequalities than the following one:

$$
\mu>\frac{48}{\left(\xi_{2}-\xi_{1}\right)^{2}}
$$

in [23]. Moreover, the obtained solutions are of definite sign.

Similarly, we give existence results for several boundary value problems of type

$$
\begin{gathered}
u^{(4)}(t)= \pm f\left(t, u(t), u^{\prime \prime}(t)\right), \quad 0<t<1, \\
u(0)=u(1)=0, \quad a u^{\prime \prime}\left(\xi_{1}\right)+b u^{\prime \prime \prime}\left(\xi_{1}\right)=0, \quad c u^{\prime \prime}\left(\xi_{2}\right)+d u^{\prime \prime \prime}\left(\xi_{2}\right)=0,
\end{gathered}
$$

where the constants $a, b, c$, and $d \geq 0$ are chosen suitable positive. At these cases, we do not use the related Green's function. Thus, our approach is applicable in cases where we cannot construct a Green's function or at least it is not of definite sign. For example, instead of the above linear boundary conditions, we could choose the following nonlinear one:

$$
u(0)=u(1)=0, \quad a u^{\prime \prime}\left(\xi_{1}\right)+b\left[u^{\prime \prime \prime}\left(\xi_{1}\right)\right]^{5 / 8}=0, \quad c u^{\prime \prime}\left(\xi_{2}\right)+d u^{\prime \prime \prime}\left(\xi_{2}\right)=0
$$

At such cases, the Krasnoselskii's fixed point theorem in a cone seems not to be applicable. Furthermore, we prove the existence of an entire continuum of solutions (Remark 2.3) and, to the best of our knowledge, this is the first result of this type of multiplicity.

Remark 1.2. Assume the nonlinearity is nonnegative. The differential Equation (1.9) defines a vector field, the properties of which will be crucial for our study. More specifically, assuming that $a d-b c>0$, we set $v(t)=u^{\prime \prime}(t)$. Let us now look (see the Figure 1, case "Th 2.2") at the $\left(v, v^{\prime}\right)$ phase quadrant $\left\{\left(v, v^{\prime}\right): v \leq 0\right.$ and $\left.v^{\prime} \geq 0\right\}$. By the sign condition on $f$, we obtain that $v^{\prime \prime}>0$. Thus any trajectory $\left(v(t), v^{\prime}(t)\right), t \geq 0$, crossing the semiline as

$$
E_{0}:=\left\{\left(v, v^{\prime}\right): a v+b v^{\prime}=0, v<0\right\},
$$

at time $t=\xi_{1}$, "evolutes" naturally, toward the negative semiline

$$
E_{1}:=\left\{\left(v, v^{\prime}\right): c v+d v^{\prime}=0, v<0\right\} .
$$

Setting a certain growth rate on $f$ (say superlinearity), we can control the vector field, so that some trajectory reaches on $E_{1}$ at the time $t=\xi_{2}$. Whenever the nonlinearity is nonpositive or/and the sign of constants different, trajectories have an analogous behavior.

The technique presented here is different to those in the above mentioned papers. Actually, we rely on the above "properties of the vector field" and the Kneser's property (continuum) of the cross-sections of the solutions funnel. For completeness, we restate the well-known Kneser's theorem. 

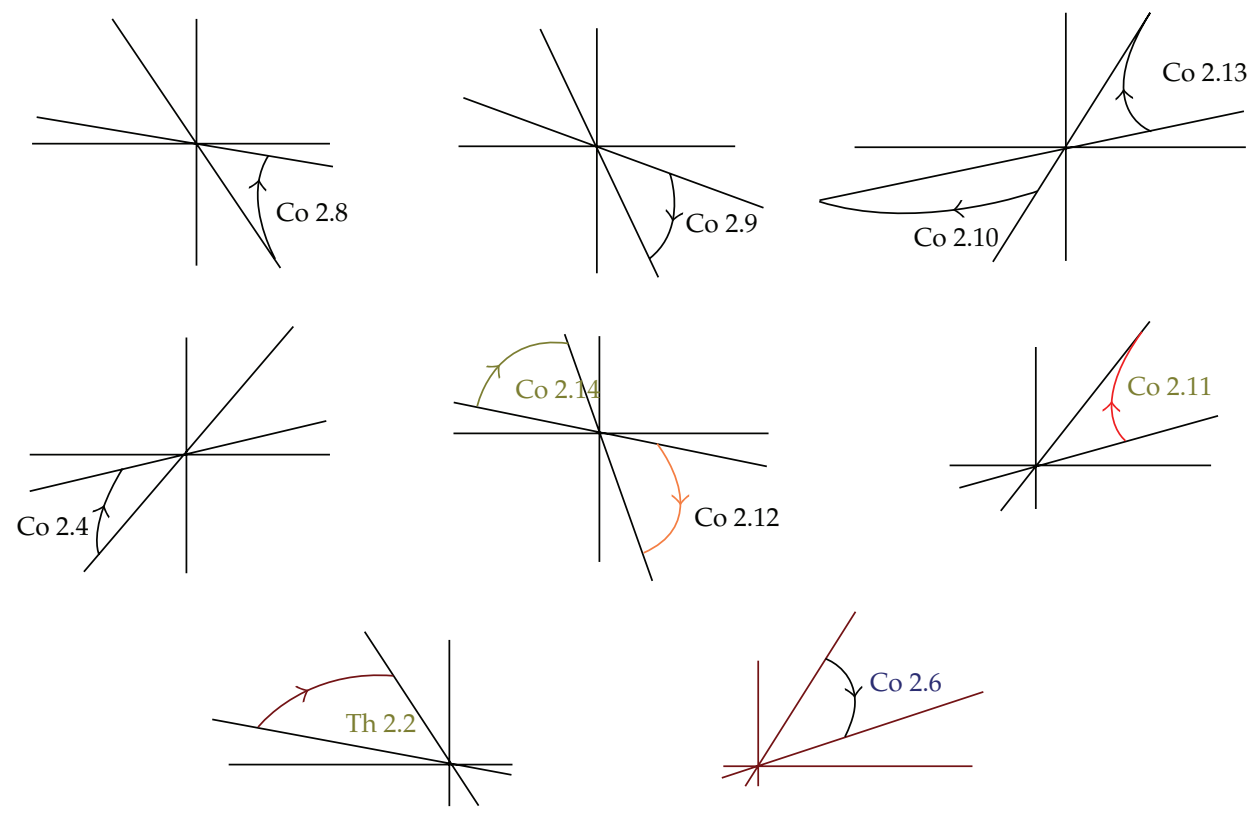

Figure 1: Vector fields and Trajectories of BVP's solutions.

Theorem 1.3 (see [25]). Consider a system $(*) x^{\prime}=f(t, x),(t, x) \in \Omega:=[a, b] \times \mathbb{R}^{n}$, with $f$ continuous. Let $\widehat{E}_{0}$ be a continuum (compact and connected) in $\Omega_{0}:=\{(t, x) \in \Omega: t=a\}$ and let $\chi\left(\widehat{E}_{0}\right)$ be the family of all solutions of $(*)$ emanating from $\widehat{E}_{0}$. If any solution $x \in X\left(\widehat{E}_{0}\right)$ is defined on the interval $[a, \tau]$, then the set (cross-section)

$$
\chi\left(\tau ; \widehat{E}_{0}\right):=\left\{x(\tau): x \in \mathcal{X}\left(\widehat{E}_{0}\right)\right\}
$$

is a continuum in $\mathbb{R}^{n}$.

\section{Main Results}

Consider the boundary value problem following:

$$
\begin{gathered}
u^{(4)}(t)=f\left(t, u(t), u^{\prime \prime}(t)\right), \quad 0<t<1, \\
u(0)=u(1)=0, \\
a u^{\prime \prime}\left(\xi_{1}\right)+b u^{\prime \prime \prime}\left(\xi_{1}\right)=0, \quad c u^{\prime \prime}\left(\xi_{2}\right)+d u^{\prime \prime \prime}\left(\xi_{2}\right)=0 .
\end{gathered}
$$

Setting $v(t)=u^{\prime \prime}(t)$, the boundary value problem $\left(\mathrm{E}_{+}\right)-\left(\mathrm{C}_{++}\right)$reduces to

$$
\begin{gathered}
v^{\prime \prime}(t)=f(t, u(t), v(t)), \quad t \in[0,1], \\
a v\left(\xi_{1}\right)+b v^{\prime}\left(\xi_{1}\right)=0, \quad c v\left(\xi_{2}\right)+d v^{\prime}\left(\xi_{2}\right)=0,
\end{gathered}
$$


where

$$
u(t)=\int_{0}^{t} s(t-1) v(s) d s+\int_{t}^{1} t(s-1) v(s) d s, \quad 0 \leq t \leq 1 .
$$

Remark 2.1. We note that for all $t \in[0,1]$, we have

$$
\begin{aligned}
& -M \leq v(t) \leq 0 \Longrightarrow 0 \leq u(t) \leq \frac{M}{8}, \quad v(t) \leq-M \Longrightarrow u(t) \geq \frac{M}{8} \\
& 0 \leq v(t) \leq M \Longrightarrow-\frac{M}{8} \leq u(t) \leq 0, \quad v(t) \geq M \Longrightarrow u(t) \leq-\frac{M}{8}
\end{aligned}
$$

Moreover, whenever we are interested in nonnegative solutions, without loss of generality, we may extend the nonlinearity as

$$
f(t, u, v)=f(t, 0,0), \quad u \leq 0, v \geq 0,
$$

and if we are asking for nonpositive solutions, we may set

$$
f(t, u, v)=f(t, 0,0), \quad u \geq 0, v \leq 0 .
$$

We will use the following assumptions.

The nonlinearity is a continuous and positive function, that is,

$$
f(t, u, v) \in C([0,1] \times(-\infty, 0] \times[0,+\infty),[0,+\infty)) ;
$$

it is asymptotically linear at the origin and at infinity, that is,

$$
\begin{gathered}
f_{0}=\lim _{u \rightarrow 0-, v \rightarrow 0+} \frac{\min _{0 \leq t \leq 1} f(t, u, v)}{v}=\mu ; \\
f_{\infty}=\lim _{u \rightarrow-\infty, v \rightarrow+\infty} \frac{\max _{0 \leq t \leq 1} f(t, u, v)}{-v}=\mu^{*} .
\end{gathered}
$$

Similarly, $f$ is a continuous and positive function, that is,

$$
f(t, u, v) \in C([0,1] \times[0,+\infty) \times(-\infty, 0],[0,+\infty))
$$


it is asymptotically linear at the origin and at infinity, that is,

$$
\begin{gathered}
f_{0}=\lim _{u \rightarrow 0+, v \rightarrow 0-} \frac{\max _{0 \leq t \leq 1} f(t, u, v)}{-v}=\mu ; \\
f_{\infty}=\lim _{u \rightarrow+\infty, v \rightarrow-\infty} \frac{\max _{0 \leq t \leq 1} f(t, u, v)}{-v}=\mu^{*} .
\end{gathered}
$$

Consider now the boundary value problem $\left(\mathrm{E}_{+}\right)-\left(\mathrm{C}_{++}\right)$.

Theorem 2.2. Assume $\left(B_{1}^{*}\right)-\left(B_{3}^{*}\right)$ hold and furthermore that

$$
a c\left(\xi_{2}-\xi_{1}\right)+a d-b c<0 .
$$

Then the boundary value problem $\left(E_{+}\right)-\left(C_{++}\right)$admits a positive and concave solution $u(t), 0 \leq t \leq 1$, provided that

$$
\begin{gathered}
\mu<\frac{2(b c-a d)-2 a c\left(\xi_{2}-\xi_{1}\right)}{\left(2 b d+b c\left(\xi_{2}-\xi_{1}\right)\right)\left(\xi_{2}-\xi_{1}\right)}:=\mu_{0}, \\
\mu^{*}>\max \left(\frac{b c-a d}{b d\left(\xi_{2}-\xi_{1}\right)}, \frac{8 c(b c-a d)}{b d^{2}}\right):=\mu_{0}^{*} .
\end{gathered}
$$

Furthermore,

$$
u^{\prime \prime}(t) \leq 0, \quad u^{\prime \prime \prime}(t) \geq 0, \quad 0 \leq t \leq 1
$$

Proof. By the asymptotic linearity of $f(t, u, v)$ at $v=0$ (see the assumption $\left(B_{2}^{*}\right)$ ) and (2.3)(2.7), for any $\lambda \in\left(\mu, \mu_{0}\right)$ there is an $\eta>0$ such that

$$
-\eta \leq v<0, \quad 0<u \leq \frac{\eta}{8}, \quad \text { imply } \max _{0 \leq t \leq 1} f(t, u, v)<-\lambda v .
$$

Consider any positive number $\varepsilon$, such that

$$
\frac{a d+\mu b d\left(\xi_{2}-\xi_{1}\right)}{b c}<\varepsilon<\frac{2 b-\left(\mu b\left(\xi_{2}-\xi_{1}\right)+2 a\right)\left(\xi_{2}-\xi_{1}\right)}{2 b}<1
$$

and choose a positive $\lambda$, where

$$
\lambda<\min \left\{\frac{\varepsilon b c-a d}{b d\left(\xi_{2}-\xi_{1}\right)}, \frac{2}{b\left(\xi_{2}-\xi_{1}\right)^{2}}\left[b(1-\varepsilon)-a\left(\xi_{2}-\xi_{1}\right)\right]\right\} .
$$

We assert that for $P_{0}^{*}=\left(v_{0},-(a / b) v_{0}\right)$ and any solution $v \in \mathcal{X}\left(P_{0}^{*}\right)$, where $v_{0}=-\eta$, it follows that

$$
-\eta \leq v(t) \leq-\varepsilon \eta, \quad t \in\left[\xi_{1}, \xi_{2}\right]
$$


Indeed in view of Remark 1.2, let us assume that there exists $t^{*} \in\left(\xi_{1}, \xi_{2}\right]$ such that

$$
-\eta \leq v(t) \leq-\varepsilon \eta, \quad v^{\prime}(t)>0, \quad \xi_{1} \leq t<t^{*}, \quad v\left(t^{*}\right)=-\varepsilon \eta .
$$

Then by the Taylor's formula, (2.10) and (2.14), we get $\bar{t} \in\left(0, t^{*}\right)$, such that

$$
\begin{aligned}
-\varepsilon \eta & =v\left(t^{*}\right)=v_{0}\left[1-\frac{a}{b}\left(t^{*}-\xi_{1}\right)\right]+\frac{\left(t^{*}-\xi_{1}\right)^{2}}{2 !} f(\bar{t}, u(\bar{t}), v(\bar{t})) \\
& \leq-\eta\left[1-\frac{a\left(t^{*}-\xi_{1}\right)}{b}\right]-\frac{\left(t^{*}-\xi_{1}\right)^{2}}{2} \lambda v(\bar{t}) \leq-\eta\left[1-\frac{a}{b}\left(\xi_{2}-\xi_{1}\right)\right]+\frac{\left(\xi_{2}-\xi_{1}\right)^{2}}{2} \lambda \eta .
\end{aligned}
$$

Consequently,

$$
\lambda \geq \frac{2}{b\left(\xi_{2}-\xi_{1}\right)^{2}}\left[b(1-\varepsilon)-a\left(\xi_{2}-\xi_{1}\right)\right]
$$

contrary to the choice of $\lambda$ in (2.12). Hence, the assertion $v(t) \leq-\varepsilon \eta, t \in\left[\xi_{1}, \xi_{2}\right]$ in (2.13) is proved. Moreover, if there is $t^{*} \in\left(\xi_{1}, \xi_{2}\right)$ such that

$$
\frac{a \eta}{b} \leq v^{\prime}(t) \leq \frac{c \varepsilon \eta}{d}, \quad \xi_{1} \leq t<t^{*}, \quad v^{\prime}\left(t^{*}\right)=\frac{c \eta \varepsilon}{d}
$$

then

$$
\begin{aligned}
\frac{c \eta \varepsilon}{d} & =v^{\prime}\left(t^{*}\right)=-v_{0} \frac{a}{b}+\left(t^{*}-\xi_{1}\right) f(\bar{t}, u(\bar{t}), v(\bar{t})) \leq \frac{a \eta}{b}-\left(t^{*}-\xi_{1}\right) \lambda v(\bar{t}) \\
& \leq \frac{a \eta}{b}-\left(t^{*}-\xi_{1}\right) \lambda v\left(\xi_{1}\right)=\frac{a \eta}{b}+\left(t^{*}-\xi_{1}\right) \lambda \eta \leq \frac{a \eta}{b}+\left(\xi_{2}-\xi_{1}\right) \lambda \eta,
\end{aligned}
$$

a contradiction to (2.12). Thus

$$
\frac{a \eta}{b} \leq v^{\prime}(t) \leq \frac{c \varepsilon \eta}{d}, \quad \xi_{1} \leq t<\xi_{2}
$$

Consequently,

$$
G^{*}\left(P_{0}^{*}\right)=c v\left(\xi_{2}\right)+d v^{\prime}\left(\xi_{2}\right) \leq c(-\eta \varepsilon)+d \frac{c \varepsilon \eta}{d}=0
$$

On the other hand, in order to prove the opposite inequality, we assume on the contrary that for every solution $v \in \mathcal{X}\left(P_{1}^{*}\right), P_{1}^{*}=(-H,(a / b) H)$, we have

$$
G^{*}\left(t ; P_{0}^{*}\right)=c v(t)+d v^{\prime}(t)<0, \quad \xi_{1} \leq t<\xi_{2}
$$


Then,

$$
v^{\prime}(t)<-\frac{c}{d} v(t), \quad \xi_{1} \leq t<\xi_{2}
$$

In view of the assumption $\left(B_{3}^{*}\right)$, we chose $K>0$ and $\theta \in(0,1)$ such that

$$
\max \left\{\frac{b c-a d}{b d\left(\xi_{2}-\xi_{1}\right) \theta}, \frac{2 c(b c-a d)}{b d^{2}(1-\theta) \theta}\right\}<K<\mu^{*}
$$

Then, there exists $H>0$, such that

$$
f(t, u, v)>-K v, \quad v \leq-\theta H
$$

Assume that there is a solution $v \in \mathcal{X}\left(P_{1}^{*}\right)$ and $t^{*} \in\left(\xi_{1}, \xi_{2}\right)$ such that

$$
-H \leq v(t) \leq-\theta H, \quad \xi_{1} \leq t<t^{*}, \quad v\left(t^{*}\right)=-\theta H .
$$

We assert first that

$$
t^{*} \geq \xi_{1}+\frac{d}{c}(1-\theta)
$$

Indeed, by (2.22) and (2.25), we obtain

$$
-\theta H=v\left(t^{*}\right) \leq-H+\frac{c}{d} H\left(t^{*}-\xi_{1}\right),
$$

and then (2.26) follows.

By (2.24)-(2.25), we obtain

$$
\begin{aligned}
-\theta H & =v\left(t^{*}\right)=-H+\frac{a}{b} H\left(t^{*}-\xi_{1}\right)+\frac{\left(t^{*}-\xi_{1}\right)^{2}}{2 !} f(\bar{t}, u(\bar{t}), v(\bar{t})) \\
& \geq-H\left[1-\frac{a}{b}\left(t^{*}-\xi_{1}\right)\right]-\frac{\left(t^{*}-\xi_{1}\right)^{2}}{2 !} K v(\bar{t}) \\
& \geq-H\left[1-\frac{a}{b}\left(t^{*}-\xi_{1}\right)\right]+\frac{\left(t^{*}-\xi_{1}\right)^{2}}{2 !} K \theta H .
\end{aligned}
$$

Consequently, (2.26) yields

$$
K \leq \frac{2\left[(1-\theta) /\left(t^{*}-\xi_{1}\right)-a / b\right]}{\left(t^{*}-\xi_{1}\right) \theta}<\frac{2 c(b c-a d)}{b d^{2}(1-\theta) \theta}
$$

a contradiction to the choice of $K$. Thus,

$$
-H \leq v(t) \leq-\theta H, \quad \xi_{1} \leq t<\xi_{2} .
$$


Consequently, by the choice of $K$ and (2.24), we get

$$
\begin{aligned}
v^{\prime}\left(\xi_{2}\right) & =\frac{a}{b} H+\left(\xi_{2}-\xi_{1}\right) f(\bar{t}, u(\bar{t}), v(\bar{t})) \\
& \geq \frac{a}{b} H-\left(\xi_{2}-\xi_{1}\right) K v(\bar{t}) \geq \frac{a}{b} H+\left(\xi_{2}-\xi_{1}\right) K H \theta \\
& \geq H\left[\frac{a}{b}+\left(\xi_{2}-\xi_{1}\right) \frac{b c-a d}{b d\left(\xi_{2}-\xi_{1}\right)}\right]=\frac{c}{d} H .
\end{aligned}
$$

Hence, we conclude that

$$
G^{*}\left(P_{1}^{*}\right)=c v\left(\xi_{2}\right)+d v^{\prime}\left(\xi_{2}\right) \geq c(-H)+d \frac{c}{d} H=0,
$$

contrary to the assertion (2.21).

Finally, consider the segment (recall that $v_{0}=-\eta_{0}$ and $v_{1}=-H$ )

$$
\left[P_{0}^{*}, P_{1}^{*}\right]:=\left\{\left(v, v^{\prime}\right) \in E_{0}: v_{0} \leq v \leq v_{1}\right\}
$$

and furthermore the cross-section

$$
\mathcal{X}\left(1 ;\left[P_{0}^{*}, P_{1}^{*}\right]\right):=\left\{\left(v(1), v^{\prime}(1)\right): v \in \mathcal{X}(P), P \in\left[P_{0}^{*}, P_{1}^{*}\right]\right\}
$$

of the solutions funnel emanating from the segment $\left[P_{0}^{*}, P_{1}^{*}\right]$. By the definition of the function $G^{*}\left(P_{1}\right):=c v\left(\xi_{2}\right)+d v^{\prime}\left(\xi_{2}\right),(2.20)$, and (2.32), it is clear (recall that $E_{1}:=\left\{\left(v, v^{\prime}\right): c v+d v^{\prime}=\right.$ $0, v>0\})$ that

$$
E_{1} \cap \mathcal{X}\left(1 ;\left[P_{0}^{*}, P_{1}^{*}\right]\right) \neq \emptyset
$$

This means that there is a point $P \in\left[P_{0}^{*}, P_{1}^{*}\right]$ such that $G^{*}(P)=0$ and thus a solution $v_{0}(t) \in$ $\chi(P)$ satisfying the second boundary condition in $\left(\mathrm{C}_{++}\right)$.

Furthermore, by the above analysis, the obtained solution $v_{0}(t), \xi_{1} \leq t \leq \xi_{2}$ is negative. We extend $v_{0}(t)$ on the entire interval as follows:

$$
v(t)= \begin{cases}v_{0}\left(\xi_{1}\right), & 0 \leq t \leq \xi_{1} \\ v_{0}(t), & \xi_{1} \leq t \leq \xi_{2} \\ v_{0}\left(\xi_{2}\right), & \xi_{2} \leq t \leq 1\end{cases}
$$

Then, the function $v(t), 0 \leq t \leq 1$, is negative and continuous. In view of the transformation $v(t)=u^{\prime \prime}(t)$, we consider the boundary value problem as

$$
\begin{gathered}
u^{\prime \prime}=v(t), \\
u(0)=0=u(1) .
\end{gathered}
$$


It is well known that the Green function of it is

$$
G(t, s)= \begin{cases}s(1-t), & 0 \leq s \leq t \leq 1 \\ t(1-s), & 0 \leq t \leq s \leq 1\end{cases}
$$

Consequently (see (2.3)), the desired positive and concave solution of the boundary value problem $\left(E_{+}\right)-\left(C_{++}\right)$is given by the formula as

$$
u(t)=\int_{0}^{1} G(t, s) v(s) d s=-\int_{0}^{t} s(t-1) v(s) d s-\int_{t}^{1} t(s-1) v(s) d s, \quad 0 \leq t \leq 1 .
$$

Remark 2.3. Since we can extend the solution $v_{0}(t), \xi_{1} \leq t \leq \xi_{2}$ with infinite ways, we can immediately obtain an entire continuum of solutions for the boundary value problem $\left(\mathrm{E}_{+}\right)$$\left(\mathrm{C}_{++}\right)$.

Consider the boundary conditions

$$
\begin{gathered}
u(0)=u(1)=0 \\
a u^{\prime \prime}\left(\xi_{1}\right)-b u^{\prime \prime \prime}\left(\xi_{1}\right)=0, \quad c u^{\prime \prime}\left(\xi_{2}\right)-d u^{\prime \prime}\left(\xi_{2}\right)=0 .
\end{gathered}
$$

Corollary 2.4. Assume $\left(B_{1}^{*}\right)-\left(B_{3}^{*}\right)$ hold, where the interval $[0,1]$ is replaced by $[-1,0]$, and furthermore

$$
a c\left(\xi_{2}-\xi_{1}\right)+b c-a d<0 .
$$

Then the boundary value problem $\left(E_{+}\right)-\left(C_{--}\right)$has a positive and concave solution $u(t), 0 \leq t \leq 1$, provided that

$$
\begin{gathered}
\mu<\frac{2(a d-b c)-2 a c\left(\xi_{2}-\xi_{1}\right)}{\left(2 b d+b c\left(\xi_{2}-\xi_{1}\right)\right)\left(\xi_{2}-\xi_{1}\right)}, \\
\mu^{*}>\max \left\{\frac{(a d-b c)}{b d\left(\xi_{2}-\xi_{1}\right)}, \frac{8 a(a d-b c)}{d b^{2}}\right\} .
\end{gathered}
$$

\section{Furthermore,}

$$
u^{\prime \prime}(t) \leq 0, \quad u^{\prime \prime \prime}(t) \leq 0, \quad 0 \leq t \leq 1
$$


Proof. Consider the BVP

$$
\begin{gathered}
y^{(4)}(t)=F\left(t, y(t), y^{\prime \prime}(t)\right), \quad-1<t<0, \\
u(-1)=u(0)=0, \\
c u^{\prime \prime}\left(-\xi_{2}\right)+d u^{\prime \prime \prime}\left(-\xi_{2}\right)=0, \quad a u^{\prime \prime}\left(-\xi_{1}\right)+b u^{\prime \prime}\left(-\xi_{1}\right)=0,
\end{gathered}
$$

where

$$
F\left(-t, u(t), u^{\prime \prime}(t)\right)=f\left(t, u(t), u^{\prime \prime}(t)\right)
$$

and $u(t),-1 \leq t \leq 0$ is any real map.

Since $f$ satisfies the conditions $\left(B_{1}^{*}\right)-\left(B_{3}^{*}\right)$, it is obvious that the same conditions are fulfilled by $F$. Hence, in view of Theorem 2.2, the BVP (2.43) admits a positive and concave solution $y(t),-1 \leq t \leq 0$. Thus, setting

$$
u(t)=y(-t), \quad 0 \leq t \leq 1,
$$

we get

$$
\begin{aligned}
u^{(4)}(t) & =(y(-t))^{(4)}=F\left(-t, y(-t), y^{\prime \prime}(-t)\right) \\
& =F\left(-t, u(t), u^{\prime \prime}(t)\right)=f\left(t, u(t), u^{\prime \prime}(t)\right), \quad 0 \leq t \leq 1
\end{aligned}
$$

Consequently, $u(t), 0 \leq t \leq 1$, is a solution of the differential equation $\left(\mathrm{E}_{+}\right)$. Furthermore the boundary conditions in (2.43) and the transformation $u(t)=y(-t), 0 \leq t \leq 1$ guarantee that the boundary conditions $\left(\mathrm{C}_{--}\right)$also hold. Hence, $u(t)$ is the requite solution of $\left(\mathrm{E}_{+}\right)-\left(\mathrm{C}_{--}\right)$.

Remark 2.5. Obviously, we could give an analytical proof (similar to the one given at Theorem 2.2) to the above Corollary 2.4, as well as to the following ones.

Consider now the differential equation as

$$
u^{(4)}(t)=-f\left(t, u(t), u^{\prime \prime}(t)\right), \quad 0<t<1,
$$

and then the boundary value problem $\left(\mathrm{E}_{-}\right)-\left(\mathrm{C}_{--}\right)$,

Corollary 2.6. Assume $\left(B_{1}\right)-\left(B_{3}\right)$ hold and furthermore that

$$
a c\left(\xi_{2}-\xi_{1}\right)+b c-a d>0 .
$$

Then the boundary value problem $\left(E_{-}\right)-\left(C_{--}\right)$admits a negative and convex solution $u(t), 0 \leq t \leq 1$, provided that (2.7)-(2.8) holds. Furthermore,

$$
u^{\prime \prime}(t) \geq 0, \quad u^{\prime \prime \prime}(t) \geq 0, \quad 0 \leq t \leq 1
$$


Proof. Consider the BVP

$$
\begin{gathered}
y^{(4)}(t)=F\left(t, y(t), y^{\prime \prime}(t)\right), \quad-1 \leq t \leq 0, \\
y(-1)=y(0)=0, \\
c y^{\prime \prime}\left(-\xi_{2}\right)+d y^{\prime \prime \prime}\left(-\xi_{2}\right)=0, \quad a y^{\prime \prime}\left(-\xi_{1}\right)+b y^{\prime \prime \prime}\left(-\xi_{1}\right)=0,
\end{gathered}
$$

where, for any real function $u(t), 0 \leq t \leq 1$,

$$
F\left(t, u(t), u^{\prime \prime}(t)\right):=f\left(-t,-u(-t),-u^{\prime \prime}(-t)\right), \quad-1 \leq t \leq 0 .
$$

Then, since the conditions $\left(B_{1}\right)-\left(B_{3}\right)$ are performed by $f, F$ satisfies the assumptions $\left(B_{1}^{*}\right)$ $\left(B_{3}^{*}\right)$ (applied on the interval $[-1,0]$ ). Hence, by Theorem 2.2, $(2.49)$ admits a positive and concave solution $y(t),-1 \leq t \leq 0$. We set

$$
u(t)=-y(-t), \quad 0 \leq t \leq 1
$$

Then

$$
\begin{aligned}
u^{(4)}(t) & =(-y(-t))^{(4)}=-(y(-t))^{(4)}=-F\left(-t, y(-t), y^{\prime \prime}(-t)\right) \\
& =-F\left(-t,-u(t),-u^{\prime \prime}(t)\right)=-f\left(t, u(t), u^{\prime \prime}(t)\right), \quad 0 \leq t \leq 1,
\end{aligned}
$$

that is, the map $u(t), 0 \leq t \leq 1$, is a solution of $\left(\mathrm{E}_{-}\right)$. Furthermore, since

$$
0=c y^{\prime \prime}\left(-\xi_{2}\right)+d y^{\prime \prime \prime}\left(-\xi_{2}\right)=-c u^{\prime \prime}\left(\xi_{2}\right)+d u^{\prime \prime \prime}\left(\xi_{2}\right)=0,
$$

(and similarly for the other) the boundary conditions in $\left(\mathrm{C}_{--}\right)$are satisfied by the solution $u(t)$. Consequently, $u(t)=-y(-t), 0 \leq t \leq 1$ is the desired solution of the boundary value problem $\left(\mathrm{E}_{-}\right)-\left(\mathrm{C}_{--}\right)$

Remark 2.7. By the following formula:

$$
y^{*}(t)=-\int_{0}^{1} G(t, s) v(s) d s=\int_{0}^{t} s(t-1) v(s) d s+\int_{t}^{1} t(s-1) v(s) d s, \quad 0 \leq t \leq 1,
$$

it is clear that the map $u^{*}(t), 0 \leq t \leq 1$, is a negative solution of the BVP (2.49). Hence we get also the positive solution as

$$
u^{*}(t)=-y^{*}(-t), \quad 0 \leq t \leq 1,
$$


of the boundary value problem $\left(\mathrm{E}_{-}\right)-\left(\mathrm{C}_{--}\right)$. The same reasoning folds for all the following results.

Consider the BVP $\left(\mathrm{E}_{+}\right)-\left(\mathrm{C}_{++}\right)$.

Corollary 2.8. Assume $\left(B_{1}\right)-\left(B_{3}\right)$ hold, and furthermore that

$$
a c\left(\xi_{2}-\xi_{1}\right)+a d-b c<0 .
$$

Then the boundary value problem $\left(E_{+}\right)-\left(C_{++}\right)$admits a negative and convex solution $u(t), 0 \leq t \leq 1$, provided that (2.7)-(2.8) holds. Furthermore,

$$
u^{\prime \prime}(t) \geq 0, \quad u^{\prime \prime \prime}(t) \leq 0, \quad 0 \leq t \leq 1
$$

Proof. Consider the BVP

$$
\begin{gathered}
y^{(4)}(t)=F\left(t, y(t), y^{\prime \prime}(t)\right), \quad 0 \leq t \leq 1, \\
y(0)=y(1)=0, \\
a y^{\prime \prime}\left(\xi_{1}\right)+b y^{\prime \prime}\left(\xi_{1}\right)=0, \quad c y^{\prime \prime}\left(\xi_{2}\right)+d y^{\prime \prime \prime}\left(\xi_{2}\right)=0,
\end{gathered}
$$

where

$$
F(t, u, v)=-f(t,-u,-v), \quad u \geq 0, v \leq 0 .
$$

Then, since the conditions $\left(B_{1}\right)-\left(B_{3}\right)$ are performed by $f, F$ satisfies the assumptions $\left(B_{1}^{*}\right)$ $\left(B_{3}^{*}\right)$ of Theorem 2.2. Hence, that BVP admits a positive and concave solution $y(t), 0 \leq t \leq 1$. We set

$$
u(t)=-y(t), \quad 0 \leq t \leq 1
$$

Then

$$
(-u(t))^{(4)}=y^{(4)}(t)=F\left(t, y(t), y^{\prime \prime}(t)\right)=-f\left(t,-y(t),-y^{\prime \prime}(t)\right)=-f\left(t, u(t), u^{\prime \prime}(t)\right),
$$

that is, the map $u(t), 0 \leq t \leq 1$, is a solution of $\left(\mathrm{E}_{+}\right)$. Furthermore, since

$$
0=a y^{\prime \prime}\left(\xi_{1}\right)+b y^{\prime \prime}\left(\xi_{1}\right)=-a u^{\prime \prime}\left(\xi_{1}\right)-b u^{\prime \prime \prime}\left(\xi_{1}\right)=0,
$$


the first (and similar the other) of the boundary conditions in $\left(\mathrm{C}_{++}\right)$is satisfied. Consequently, $u(t)=-y(t), 0 \leq t \leq 1$, is the desired solution of the boundary value problem $\left(\mathrm{E}_{+}\right)-\left(\mathrm{C}_{++}\right)$.

Consider now the boundary value problem $\left(\mathrm{E}_{-}\right)-\left(\mathrm{C}_{++}\right)$.

Corollary 2.9. Assume $\left(B_{1}^{*}\right)-\left(B_{3}^{*}\right)$ hold and furthermore that $a c\left(\xi_{2}-\xi_{1}\right)+a d-b c<0$. Then the boundary value problem $\left(E_{-}\right)-\left(C_{++}\right)$admits a positive and concave solution $u(t), 0 \leq t \leq 1$, provided that (2.41) holds. Furthermore,

$$
u^{\prime \prime}(t) \geq 0, \quad u^{\prime \prime \prime}(t) \leq 0, \quad 0 \leq t \leq 1
$$

Proof. Consider any function $u(t), 0 \leq t \leq 1$. We define a map $f^{*}$ by

$$
f\left(t, u(t), u^{\prime \prime}(t)\right)=-f^{*}\left(\xi_{1}+\xi_{2}-t, u\left(\xi_{1}+\xi_{2}-t\right), u^{\prime \prime}\left(\xi_{1}+\xi_{2}-t\right)\right), \quad t \in[0,1], u \geq 0, v \leq 0 .
$$

Since $f$ satisfies the conditions $\left(B_{1}^{*}\right)-\left(B_{3}^{*}\right)$, we easily check that $f^{*}$ suits the same conditions. In view of Theorem 2.2, consider a solution $u^{*}(t), \xi_{1}+\xi_{2}-1 \leq t \leq \xi_{1}+\xi_{2}$, of the following BVP:

$$
\begin{gathered}
\left(u^{*}\right)^{(4)}(t)=f^{*}\left(t, u^{*}(t), u^{*^{\prime \prime}}(t)\right), \\
u^{*}(0)=u^{*}(1)=0, \\
c u^{* \prime \prime}\left(\xi_{1}\right)+d u^{* \prime \prime \prime}\left(\xi_{1}\right)=0, \quad a u^{* \prime \prime}\left(\xi_{2}\right)+b u^{* \prime \prime \prime}\left(\xi_{2}\right)=0 .
\end{gathered}
$$

We notice that $\xi_{1}+\xi_{2}-1 \leq \xi_{1}<\xi_{2} \leq \xi_{1}+\xi_{2}$ and set

$$
u(t) \equiv u^{*}\left(\xi_{1}+\xi_{2}-t\right), \quad 0 \leq t \leq 1
$$

Then, we obtain

$$
\begin{aligned}
(u(t))^{(4)} & =\left(u^{*}\left(\xi_{1}+\xi_{2}-t\right)\right)^{(4)} \\
& =f^{*}\left(\xi_{1}+\xi_{2}-t, u^{*}\left(\xi_{1}+\xi_{2}-t\right), u^{* \prime \prime}\left(\xi_{1}+\xi_{2}-t\right)\right)=-f(t, u(t), v(t)),
\end{aligned}
$$

that is, the function $u(t), 0 \leq t \leq 1$ is a solution of the differential equation ( $\left.\mathrm{E}_{-}\right)$. Moreover, the boundary conditions $\left(\mathrm{C}_{++}\right)$are satisfied by the function $u(t)$, since the solution $u^{*}(t)$ fulfils the boundary conditions (2.66). Consequently, $u(t)$ is the requite solution of $\left(\mathrm{E}_{-}\right)-\left(\mathrm{C}_{++}\right)$.

Corollary 2.10. Assume $\left(B_{1}\right)-\left(B_{3}\right)$ hold and furthermore that $a c\left(\xi_{2}-\xi_{1}\right)+a d-b c<0$. Then the boundary value problem $\left(E_{-}\right)-\left(C_{++}\right)$admits a positive and concave solution $u(t), 0 \leq t \leq 1$, provided that (2.41) holds. Furthermore,

$$
u^{\prime \prime}(t) \geq 0, \quad u^{\prime \prime \prime}(t) \leq 0, \quad 0 \leq t \leq 1 .
$$


Proof. It follows by Corollary 2.9, via the following transformation:

$$
u(t)=y(-t), \quad 0 \leq t \leq 1
$$

Here $y(t),-1 \leq t \leq 0$, is a positive solution of the BVP as

$$
\begin{gathered}
y^{(4)}(t)=F\left(t, y(t), y^{\prime \prime}(t)\right), \quad-1 \leq t \leq 0, \\
u(0)=u(1)=0, \\
c u^{\prime \prime}\left(-\xi_{2}\right)+d u^{\prime \prime \prime}\left(-\xi_{2}\right)=0, \quad a u^{\prime \prime}\left(-\xi_{1}\right)+b u^{\prime \prime}\left(-\xi_{1}\right)=0,
\end{gathered}
$$

where

$$
F\left(t, u(-t), u^{\prime \prime}(-t)\right)=-f\left(-t, u(t), u^{\prime \prime}(t)\right), \quad-1 \leq t \leq 0 .
$$

Indeed, for $t \in[0,1]$,

$$
u^{(4)}(t)=(y(-t))^{(4)}=F\left(-t, y(-t), y^{\prime \prime}(-t)\right)=F\left(-t, u(t), u^{\prime \prime}(t)\right)=-f\left(t, u(t), u^{\prime \prime}(t)\right)
$$

that is, $u(t), t \in[0,1]$, is a solution of differential equation ( $\left.\mathrm{E}_{-}\right)$. Finally, $u(t)=y(-t),-1 \leq$ $t \leq 0$, is a desired solution of BVP ( $\left.\mathrm{E}_{-}\right)-\left(\mathrm{C}_{--}\right)$.

Similarly, we may prove the next results.

Corollary 2.11. Assume $\left(B_{1}\right)-\left(B_{3}\right)$ hold and furthermore,

$$
a c\left(\xi_{2}-\xi_{1}\right)+b c-a d<0 .
$$

Then the boundary value problem $\left(E_{+}\right)-\left(C_{--}\right)$has a negative and convex solution $u(t), 0 \leq t \leq 1$, provided that (2.7)-(2.8) holds. Furthermore,

$$
u^{\prime \prime}(t) \geq 0, \quad u^{\prime \prime \prime}(t) \geq 0, \quad 0 \leq t \leq 1
$$

Corollary 2.12. Assume $\left(B_{1}\right)-\left(B_{3}\right)$ hold and furthermore

$$
a c\left(\xi_{2}-\xi_{1}\right)+b c-a d<0 .
$$

Then the boundary value problem $\left(E_{-}\right)-\left(C_{++}\right)$has a negative and convex solution $u(t), 0 \leq t \leq 1$, provided that (2.41) holds. Furthermore,

$$
u^{\prime \prime}(t) \geq 0, \quad u^{\prime \prime \prime}(t) \leq 0, \quad 0 \leq t \leq 1 .
$$


Corollary 2.13. Assume $\left(B_{1}\right)-\left(B_{3}\right)$ hold and furthermore

$$
a c\left(\xi_{2}-\xi_{1}\right)+a d-b c<0 .
$$

Then the boundary value problem $\left(E_{-}\right)-\left(C_{--}\right)$has a negative and convex solution $u(t), 0 \leq t \leq 1$, provided that (2.7)-(2.8) holds. Furthermore,

$$
u^{\prime \prime}(t) \geq 0, \quad u^{\prime \prime \prime}(t) \geq 0, \quad 0 \leq t \leq 1
$$

Corollary 2.14. Assume that $\left(B_{1}^{*}\right)$ holds and the nonlinearity is a sublinear map, that is, $\mu=0$, $\mu^{*}=+\infty$. Then, the boundary value problem $\left(E_{+}\right)-\left(C_{++}\right)$admits a positive and concave solution.

Proof. Obviously, $\left(B_{1}^{*}\right)-\left(B_{3}^{*}\right)$ are fulfilled. Thus, Theorem 2.2, yields the result.

Remark 2.15. It is obvious that the results of all Corollaries, given above, still hold, under a sublinearity assumption of the nonlinearity (see [23]).

Remark 2.16. We could replace the following lines (initial and terminal points):

$$
E_{0}:=\left\{\left(v, v^{\prime}\right): a v+b v^{\prime}=0, v>0\right\}, \quad E_{1}:=\left\{\left(v, v^{\prime}\right): c v+d v^{\prime}=0, v>0\right\}
$$

with any suitable continuum $K_{0}$ and $K_{1}$, respectively. At such a case, the existence of the related Green's function is uncertain. For example, we may consider the following boundary conditions:

$$
a\left(u^{\prime \prime}\left(\xi_{1}\right)\right)^{3}+b u^{\prime \prime \prime}\left(\xi_{1}\right)=0, \quad c\left(u^{\prime \prime}\left(\xi_{2}\right)\right)^{1 / 3}+b u^{\prime \prime \prime}\left(\xi_{2}\right)=0 .
$$

Then, the proof can be carried out word perfect.

\section{Disclosure}

This paper is in final form and no version of it will be submitted for publication elsewhere.

\section{References}

[1] S. P. Timoshenko, Theory of Elastic Stability, McGraw-Hill Book, New York, NY, USA, 1961.

[2] W. Soedel, Vibrations of Shells and Plates, Dekker, New York, NY, USA, 1993.

[3] P. K. Palamides, "Boundary-value problems for shallow elastic membrane caps," IMA Journal of Applied Mathematics, vol. 67, no. 3, pp. 281-299, 2002.

[4] E. Dulàcska, "Soil Settlement Effects on Buildings," in Developments in Geotechnical Engineering, vol. 69, Elsevier, Amsterdam, The Netherlands, 1992.

[5] P. Pietramala, "A note on a beam equation with nonlinear boundary conditions," Boundary Value Problems, vol. 2011, Article ID 376782, 14 pages, 2011.

[6] L. H. Erbe and H. Wang, "On the existence of positive solutions of ordinary differential equations," Proceedings of the American Mathematical Society, vol. 120, no. 3, pp. 743-748, 1994.

[7] R. P. Agarwal and D. O'Regan, "Nonlinear superlinear singular and nonsingular second order boundary value problems," Journal of Differential Equations, vol. 143, no. 1, pp. 60-95, 1998. 
[8] L. H. Erbe and K. Schmitt, "Boundary value problems for second order differential equations," Lecture Notes in Pure and Applied Mathematics, vol. 109, pp. 179-184, 1987.

[9] L. K. Jackson and P. K. Palamides, "An existence theorem for a nonlinear two-point boundary value problem," Journal of Differential Equations, vol. 53, no. 1, pp. 48-66, 1984.

[10] D. O'Regan, Theory of Singular Boundary Value Problems, World Scientific Publishing, Singapore, 1994.

[11] P. K. Palamides, “Boundary and periodic value problems for differential systems, via Sperner's lemma," Mathematica Japonica, vol. 34, no. 1, pp. 89-110, 1989.

[12] R. P. Agarwal, D. O’Regan, and P. J. Y. Wong, Positive Solutions of Differential, Difference, and Integral Equations, Kluwer Academic, Dordrecht, The Netherlands, 1998.

[13] D. R. Anderson and J. M. Davis, "Multiple solutions and eigenvalues for third-order right focal boundary value problems," Journal of Mathematical Analysis and Applications, vol. 267, no. 1, pp. 135$157,2002$.

[14] Z. Bai and H. Wang, "On positive solutions of some nonlinear fourth-order beam equations," Journal of Mathematical Analysis and Applications, vol. 270, no. 2, pp. 357-368, 2002.

[15] J. R. Graef and B. Yang, "On a nonlinear boundary value problem for fourth order equations," Applicable Analysis, vol. 72, no. 3-4, pp. 439-448, 1999.

[16] J. R. Graef and B. Yang, "Positive solutions to a multi-point higher order boundary value problem," Journal of Mathematical Analysis and Applications, vol. 316, no. 2, pp. 409-421, 2006.

[17] J. R. Graef, J. Henderson, and B. Yang, "Positive solutions of a nonlinear higher order boundary-value problem," Electronic Journal of Differential Equations, vol. 2007, no. 45, pp. 1-10, 2007.

[18] Z. Hao, L. Liu, and L. Debnath, "A necessary and sufficient condition for the existence of positive solutions of fourth-order singular boundary value problems," Applied Mathematics Letters, vol. 16, no. 3, pp. 279-285, 2003.

[19] J. Ge and C. Bai, "Solvability of a four-point boundary-value problem for fourth-order ordinary differential equations," Electronic Journal of Differential Equations, vol. 2007, no. 123, pp. 1-9, 2007.

[20] M. A. Krasnoselskii and P. P. Zabreiko, Geometrical Methods of Nonlinear Analysis, Springer, New York, NY, USA, 1984.

[21] Y. Cui and Y. Zou, "Positive solutions of singular fourth-order boundary-value problems," Electronic Journal of Differential Equations, vol. 2006, no. 39, pp. 1-10, 2006.

[22] G. Infante and P. Pietramala, "A cantilever equation with nonlinear boundary conditions," Electronic Journal of Qualitative Theory of Differential Equations, vol. 15, pp. 1-14, 2009.

[23] S. Petio Kelevedjev, K. Panos Palamides, and I. Nedyu Popivanov, "Fourth-order four-point boundary value problem," Electronic Journal of Differential Equations, vol. 2008, no. 47, pp. 1-15, 2008.

[24] D. R. Anderson and R. I. Avery, "A fourth-order four-point right focal boundary value problem," The Rocky Mountain Journal of Mathematics, vol. 36, no. 2, pp. 367-380, 2006.

[25] W. A. Copel, Stability and Asymptotic Behavior of Differential Equations, Heath \& Co, Boston, Mass, USA, 1965. 


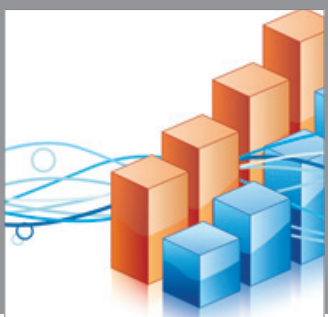

Advances in

Operations Research

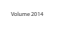

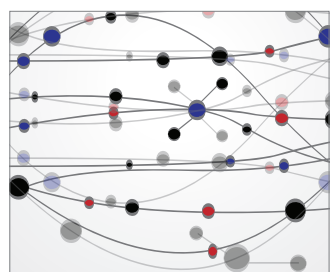

\section{The Scientific} World Journal
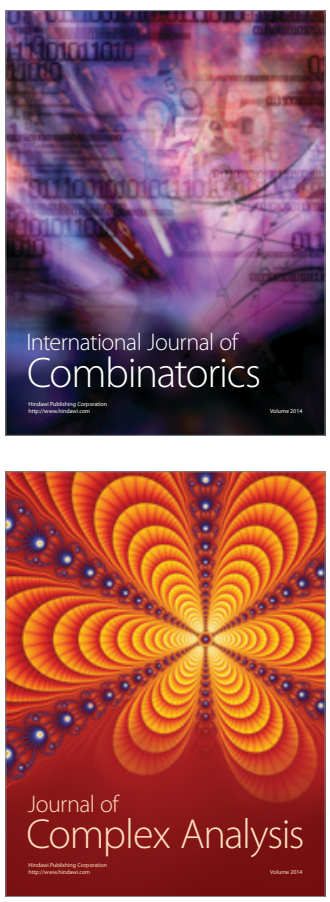

International Journal of

Mathematics and

Mathematical

Sciences
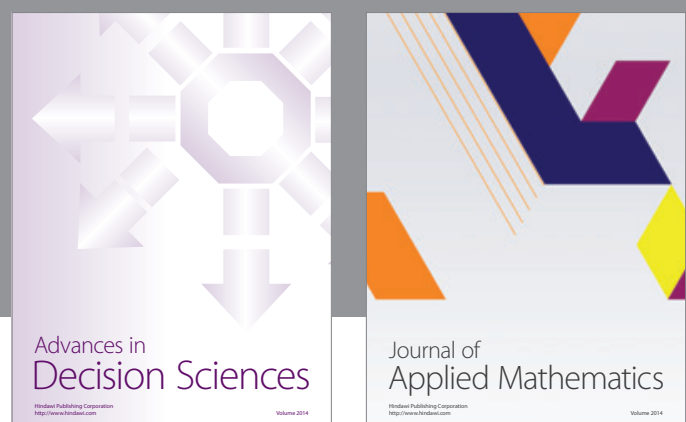

Journal of

Applied Mathematics
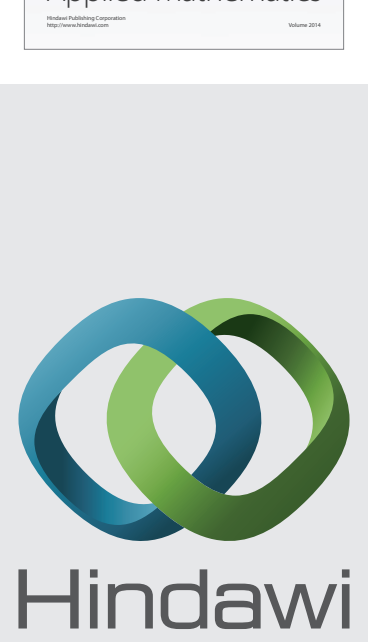

Submit your manuscripts at http://www.hindawi.com
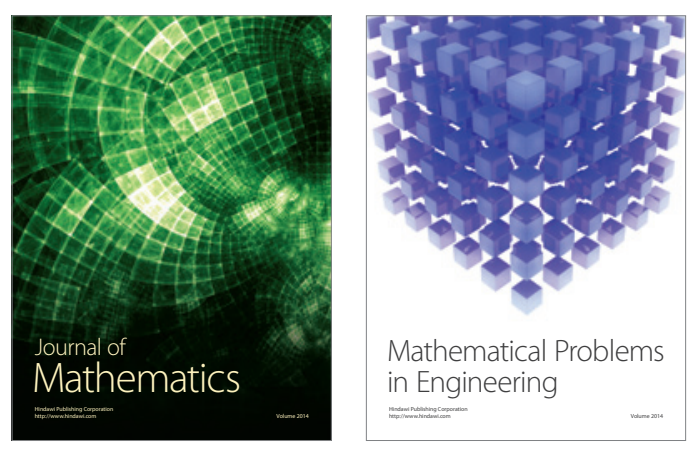

Mathematical Problems in Engineering
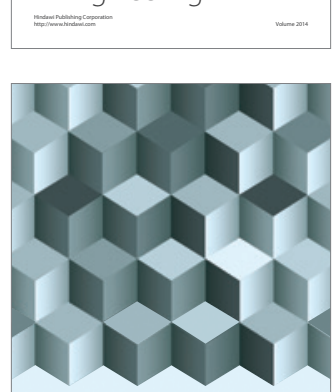

Journal of

Function Spaces
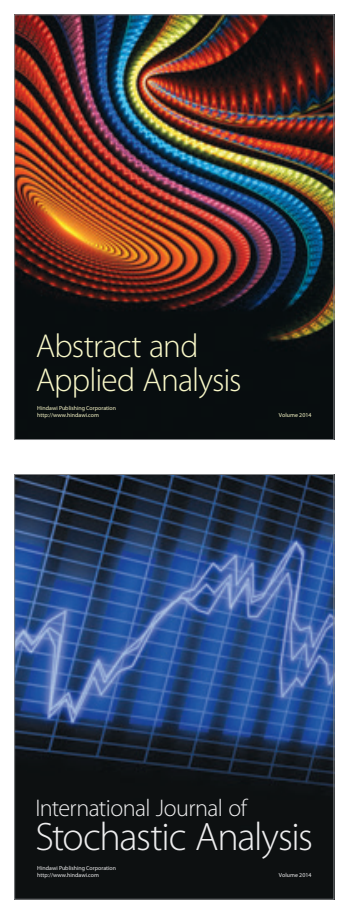

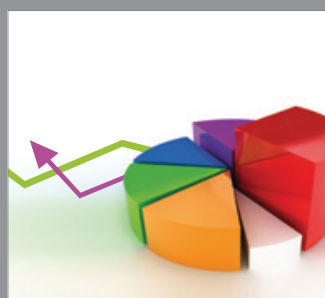

ournal of

Probability and Statistics

Promensencen
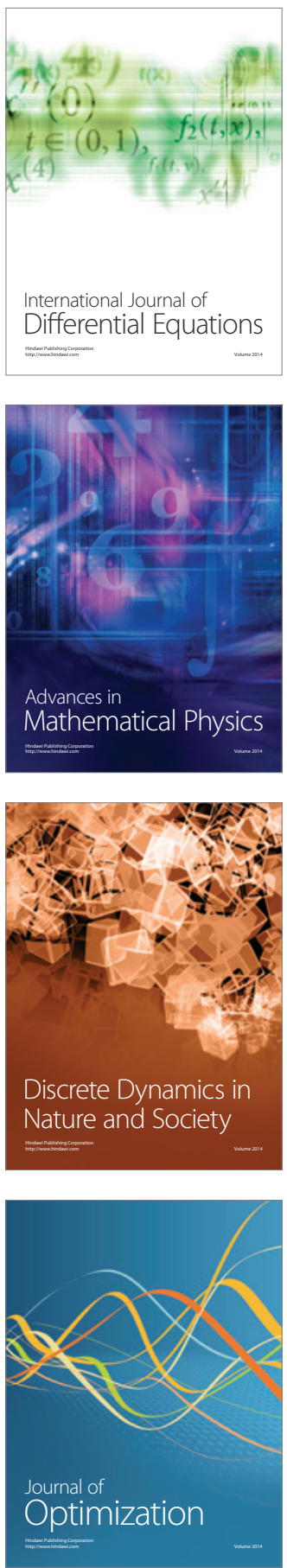